\section{INTERNATIONAL JOURNAL OF ENGINEERING, SCIENCE AND TECHNOLOGY \\ www.ijest-ng.com \\ www.ajol.info/index.php/ijest \\ (C) 2014 MultiCraft Limited. All rights reserved}

\title{
Optimization of surface roughness in turning of GFRP composites using genetic algorithm
}

\author{
Syed Altaf Hussain $^{{ }^{*}}$, V. Pandurangadu ${ }^{2}$, K. Palani Kumar ${ }^{3}$ \\ ${ }^{1 *}$ Department of Mechanical Engineering, RGM College of Engineering \&Technology, Nandyal, A.P, INDIA \\ ${ }^{2}$ Department of Mechanical Engineering, JNTUACE-Anantapur, INDIA \\ ${ }^{3}$ Department of Mechanical Engineering, Sri Sai Ram Institute of Technology, Chennai, INDIA \\ *Corresponding Author: e-mail: rgmaltaf1@gmail.com, Tel +91-9494738100, Fax.+91-08514-275123
}

\begin{abstract}
Glass fiber reinforced polymer composites are finding its increased applications in variety of engineering applications such as aerospace, automobile, electronics and other industries. However, the users of FRP are facing difficulties to machine it, because of fiber delamination, fiber pull out, short tool life, matrix debonding and formation of powder like chips. The present investigation focuses on the optimization of process parameters for surface roughness of glass fiber reinforced polymer (GFRP) composites using Genetic Algorithm (GA). Experiments are conducted based on the established Taguchi's $\mathrm{L}_{25}$ orthogonal array in Design of Experiments (DOE) on an all-geared lathe using poly-crystalline diamond (PCD) tool. The process parameters considered were cutting speed, feed, depth of cut, and work piece (fiber orientation angle). A second order mathematical model was developed for surface roughness prediction using Response Surface Methodology (RSM). An attempt has also been made to optimize the surface roughness prediction model coupling with Genetic Algorithm (GA) to optimize the objective function. Validation of the optimized results was also performed by confirmation experiments.
\end{abstract}

Keywords: GFRP composites, Response surface methodology (RSM), Poly crystalline diamond (PCD), surface roughness $\left(\mathrm{R}_{\mathrm{a}}\right)$, Genetic Algorithm (GA).

DOI: http://dx.doi.org/10.4314/ijest.v6i1.6

\section{Introduction}

Glass fiber reinforced plastics (GFRP) are increasingly being used for varieties of engineering applications because of their superior advantage over other engineering materials. The advantages include high strength to weight ratio, high fracture toughness and excellent corrosion and thermal resistance. The tailarability of composites for specific applications has been one of their greater advantages and also one of the more perplexing challenges to adopting them as alternative to conventional materials. As the application fields of FRP expand the opportunity of machining such as cutting off, drilling, milling, turning, etc. has increased for its fabrication. The machining of FRP is different from that of metal working in many respects, because the metal behavior is not only inhomogeneous, but also dependent on fiber and matrix properties, fiber orientation and the type of weave. Bhatnagar et al (1995) revealed the fact that, even though Glass fiber reinforce polymer (GFRP) tube made by filament wind technique require further machining to facilitate dimensional control for easy assembly and control of surface quality for functional aspects. König et al. (1985) demonstrated that the users of FRP are facing difficulties when machining it, because knowledge and experience acquired for conventional materials cannot be applied for such new materials, whose machinability is different from that of conventional materials. Thus, it is desirable to investigate the behavior of FRPs during the machining process. Bhatnagar et al. (1995) investigated how the fiber orientation influence both the quality of the machined surfaces and tool wear.

The machinability of composite materials is influenced by the type of fiber embedded in the composites, and more particularly by the mechanical properties. On the other hand, the selection of cutting parameters and the cutting tool are dependent on the type of fiber used in the composites and which is very important in the machining process. Tekeyama et al (1988) studied the surface roughness on machining of GFRP composites, according to them, higher cutting speed produce more damage on the machined surface. This is attributed to higher cutting temperature, which results in local softening of work material. They also studied the machinability of FRP composites using the ultrasonic machining technique. According to 
Koing et al. (1985), measurement of surface roughness in FRP is less dependable compared to that in metals, because protruding fiber tips may lead to incorrect results. Additional errors may result from the hooking of the fibers to the stylus. Palanikumar et al. (2008), studied the effect of cutting parameters on surface roughness on machining of GFRP composites by polycrystalline diamond (PCD) tool by developing a second order model for predicting the surface roughness.

Palanikumar et al. (2006) have developed a procedure to asses and optimize the chosen factors to attain minimum surface roughness by incorporating response table and response graph, normal probability plot, interaction graphs, and analysis of variance (ANOVA) technique. According to Mitsuo Gen et al. (1994) the traditional search techniques for optimization are calculus based and convergence only to a local optimum. Genetic algorithm is a guided random search technique and is directed through the search space by means of an objective function. Karthikeyan and Adalarasan (2001) have optimized the cutting parameters in machining of metal matrix composites (MMCs) using Genetic Algorithm. Palanikuamr et al (2004) optimized the machining parameter for minimum surface roughness in turning of GFRP composites using Design of Experiments. Suresh et al. (2002) developed a response surface model for surface roughness in terms of speed, feed, depth of cut and nose radius and optimized using genetic algorithm. Palanikumar et al. (2006) have applied Taguchi method with fuzzy logic to optimize the machining parameters for machining of GFRP composites with multiple characteristics. A multiResponse Performance index (MRPI) was used for optimization. Sijo and Biju (2010) have applied Taguchi parameter optimization methodology to optimize the cutting parameters in turning. The turning parameters evaluated are cutting speed, feed and depth of cut, nose radius and hardness of tool. Evolkilickap (2010) investigated the optimal drilling parameters of GFRP composites using different drills, he concluded that feed is the major parameter among the controllable factors.

Varma et al. (2011) have obtained the optimal parameters in machining of GFRP composites using fuzzy logic modeling combined with Taguchi's robust design. Hanafi et al. (2012) have performed machining studies to study the surface roughness parameters $\mathrm{R}_{\mathrm{a}}$, and $\mathrm{R}_{\mathrm{t}}$ on fiber reinforced poly ether ether ketone (PEEK) CF30 with TiN Coated tools, modeling is performed using artificial neural networks approach to represent the complex relationships between cutting conditions a surface roughness parameters. Predictions of the ANN based model were found to fit experimental data very well with correlation coefficient as high as 99\%. Quintana et al. (2012) have developed artificial neural network (ANN) model for the surface roughness in milling of wind turbine components. Surinderkumar et al. (2012) have conducted experimental study on machining of unidirectional glass fiber reinforced plastic (UD-GFRP) composite material to investigate the effect of tool nose radius, rake angle, feed rate, cutting speed, depth of cut and along with the cutting environment (dry, wet and cooled $\left(5-7^{0} \mathrm{C}\right.$ temperature) on the surface roughness produced. The experimental results reveal that the most significant machining parameters for surface roughness is feed rate followed by cutting speed. Surinderkumar et al. (2012) have developed a second order regression model for predicting the surface roughness in machining of unidirectional glass fiber reinforced plastic (UDGFRP) composite material, they also made an attempt to optimize the machining parameters to minimize the surface roughness.

In the present, the work effect of process parameters on surface roughness in the turning of GFRP composites by PCD tool has been evaluated. A second order quadratic model is developed for predicting the surface roughness in turning of GFRP composites by response surface methodology (RSM) approach. The developed response surface model was coupled with genetic algorithm to find the optimum process parameter values.

\section{Materials and Methods}

The work material used for the present investigation is glass fiber reinforced polymer (GFRP) tubes of different fiber orientation angles vary from $\left(30^{\circ}\right.$ to $\left.90^{\circ}\right)$ in steps of $15^{\circ}$. The inner diameter of the tube is $30 \mathrm{~mm}$, outer diameter is $60 \mathrm{~mm}$ and length $500 \mathrm{~mm}$ respectively as shown in figure 1 . The tubes used in the study are manufactured by filament winding process, the orientation of the fibers on the works piece has been set during manufacturing of tubes. The fiber used in the tube is Eglass and resign used is epoxy. The specification of the material used in this work is given in Table 1.

Table 1 Specifications of fiber and resin.

\begin{tabular}{|c|c|}
\hline Fiber : E-Glass-R099 1200 P556 & Resin: Epoxy \\
\hline Manufacturer : Saint Gobain & Manufacturer: CIBA GEIGY \\
\hline Vetrotex India ltd & Product: ARALDITE MY 740 IN \\
\hline R-009 - Multi filament Roving & $110 \mathrm{KG}$ Q2. \\
\hline 1200 - Linear density Tex & Hardner : HT972 \\
\hline P556 -Sizing reference for vetrotex. & \\
\hline
\end{tabular}




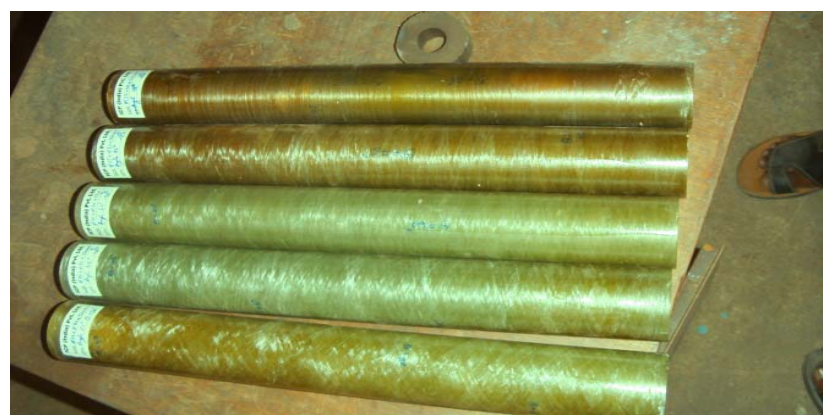

Figure 1. Specimens of GFRP Composite tubes

\subsection{Response surface methodology}

The surface finish of machined GFRP composite parts is important in manufacturing engineering applications which have considerable effect on some properties such as wear resistance, light reflection, heat transmission, coating and resisting fatigue. While machining, quality of the part can be achieved through proper cutting conditions. In order to know the surface quality and dimensional properties in advance, it is necessary to employ theoretical models making it feasible to do prediction in function of operation condition. According to Montgomery (1991) response surface methodology (RSM) is a collection of mathematical and statistical techniques that are useful for modeling and analysis of problems in which a response of interest is influenced by several variables and the objective is to optimize this response. In many engineering fields, there is a relationship between an output variable of interest ' $y$ ' and a set of controllable variables $\left\{x_{1}, x 2 \ldots \ldots x_{n}\right\}$ in some systems, the nature of relationship between $\mathrm{y}$ and $\mathrm{x}$ values might be known. Then, a model can be written in the form

$$
\mathrm{y}=\mathrm{f}\left(\mathrm{x}_{1}, \mathrm{x}_{2}, \ldots, \mathrm{x}_{\mathrm{n}}\right)+\varepsilon
$$

Where $\varepsilon$ represents noise or error observed in the response ' $y$ '

If we denote the expected response be $\mathrm{E}(\mathrm{Y})=\mathrm{f}\left(\mathrm{x}_{1}, \mathrm{x}_{2}, \ldots, \mathrm{x}_{\mathrm{n}}\right)=\mathrm{y}$ is called response surface. The first step is to find suitable approximation for the true functional relationship between y and set of independent variables employed usually a second order model is used in RSM.

$\mathrm{y}=\beta_{0}+\sum_{\mathrm{i}} \beta_{\mathrm{i}} \mathrm{x}_{\mathrm{i}}+\sum_{\mathrm{i}} \beta_{\mathrm{ij}} \mathrm{x}^{2}+\sum_{\mathrm{i}} \beta_{\mathrm{ij}} \mathrm{x}_{\mathrm{i}} \mathrm{x}_{\mathrm{j}}+\varepsilon$

The $\beta$ coefficients, used in the above model can be calculated by means of using least square method. The second-order model is normally used when the response function is not known or nonlinear.

\subsection{Genetic algorithms optimization}

Genetic algorithms are computerized optimization methods that work very similar to the principles of natural evolution. Based on Darwin's survival of-the fittest principles, GA's intelligent search procedure finds the best and fittest design solutions, otherwise difficult to find the best and fittest design solutions using other techniques. GAs is attractive in engineering design and applications because they are easy to use and they are likely to find the globally best design or solution, which is superior to any other design or solution.

\section{Experimental Details}

The experiments are conducted as per the Taguchi's orthogonal array $\mathrm{L}_{25}$ design of experiments. The four cutting parameters selected for the present investigation is cutting speed (V) $\mathrm{m} / \mathrm{min}$, feed (f) $\mathrm{mm} / \mathrm{rev}$, depth of cut (d) $\mathrm{mm}$ and work piece (fiber orientation ' $\Phi$ ') in degrees . Since the considered factors are multi-level variables and their outcome effects are not linearly related. The machining parameter used and their levels chosen are given in Table 2 . All the GFRP tubes are turned in a BHARAT all-geared lathe of model NAGMATI-175 with a maximum speed of $1200 \mathrm{rpm}$ and power of $2.25 \mathrm{KW}$. The ISO specification of the toll holder used for the turning operation is a WIDAX tool holder PC LNR 2020 K12 and the tool insert used for the study is PCD (CNMA 120408). Figure 2 shows the photo graph of the original experimental setup. The PCD cutting tool insert used in this investigation is shown in Figure 3.

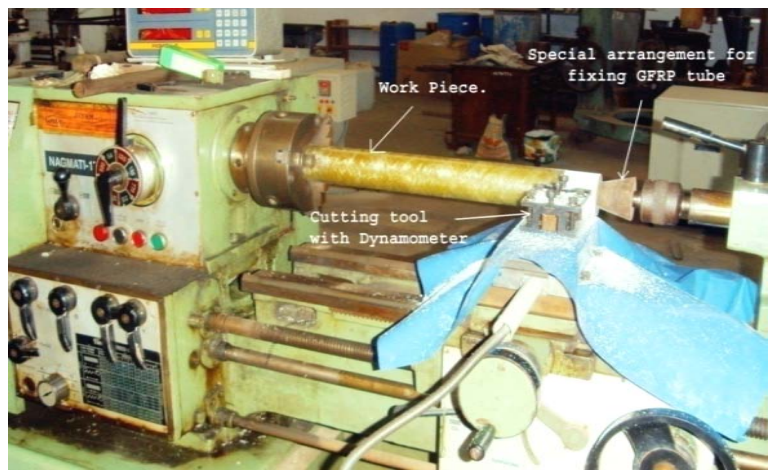

Figure 2. Photo graph of original experimental setup. 


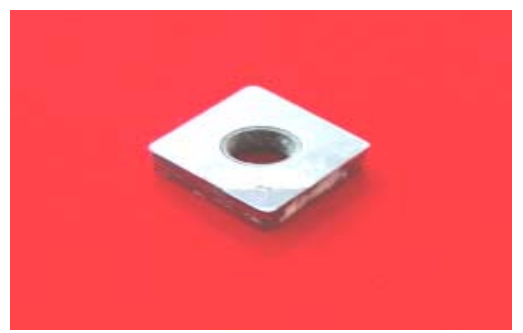

Figure. 3 Poly-Crystalline Diamond (PCD)- CNMA 120408 insert

Table 2 Process parameters and levels used for the experimentation.

\begin{tabular}{|c|c|c|c|c|c|c|c|}
\hline \multirow{2}{*}{$\begin{array}{l}\text { Process parameters } \\
\text { With units }\end{array}$} & \multirow[b]{2}{*}{ Notation } & \multirow[b]{2}{*}{ Variable } & \multicolumn{5}{|c|}{ Levels } \\
\hline & & & 1 & 2 & 3 & 4 & 5 \\
\hline Speed, $\mathrm{m} / \mathrm{min}$ & $\mathrm{V}$ & $\mathrm{x}_{1}$ & 40 & 60 & 95 & 145 & 225 \\
\hline Feed, mm/rev & f & $\mathrm{x}_{2}$ & 0.048 & 0.096 & 0.143 & 0.191 & 0.238 \\
\hline Depth of cut, mm & d & $\mathrm{x}_{3}$ & 0.25 & 0.5 & 0.75 & 1.0 & 1.25 \\
\hline $\begin{array}{l}\text { Fiber orientation } \\
\text { angle, deg }\end{array}$ & $\Phi$ & $\mathrm{x}_{4}$ & 30 & 45 & 60 & 75 & 90 \\
\hline
\end{tabular}

The average surface roughness ( $\mathrm{Ra}$ ), which is mostly used in industrial environments, is taken-up for this study. In a composite machined surface, according to Koing et al (1985) the result of the roughness depends mainly on the stylus path with respect to fiber direction since the main direction of fibers may change from layer to layer. The absolute value of the roughness profile height over the evaluation length and is denoted by the following equation. For this reason, the roughness has been measured several times and averaged. The average surface roughness is the integral of

$$
R_{a}=\frac{1}{L} \int_{0}^{L}|y(x)| d x
$$

Where $\mathrm{L}$ is the length taken for observation, and $\mathrm{Y}$ is the ordinate of the profile curve. The surface roughness was measured by using surface roughness tester (FORM TALY SURF). Table 3 shows the experimental results.

Table 3 Experimental results

\begin{tabular}{|c|c|c|c|c|c|}
\hline $\begin{array}{l}\text { Exp. } \\
\text { No. }\end{array}$ & $\begin{array}{l}\text { Cutting speed (V) } \\
\mathrm{m} / \mathrm{min}\end{array}$ & $\begin{array}{l}\text { feed (f) } \\
\mathrm{mm} / \mathrm{rev}\end{array}$ & $\begin{array}{l}\text { Depth of cut (d), } \\
\text { mm }\end{array}$ & $\begin{array}{l}\text { Fiber orientation } \\
\text { angle }(\Phi) \text { deg }\end{array}$ & $\begin{array}{c}\text { Surface roughness } \\
\left(\mathrm{R}_{\mathrm{a}}\right), \mu \mathrm{m}\end{array}$ \\
\hline 1 & 40 & 0.048 & 0.25 & 30 & 1.8695 \\
\hline 2 & 40 & 0.096 & 0.5 & 45 & 2.1894 \\
\hline 3 & 40 & 0.143 & 0.75 & 60 & 2.7291 \\
\hline 4 & 40 & 0.191 & 1.0 & 75 & 2.7959 \\
\hline 5 & 40 & 0.238 & 1.25 & 90 & 3.3284 \\
\hline 6 & 60 & 0.048 & 0.5 & 60 & 2.3406 \\
\hline 7 & 60 & 0.096 & 0.75 & 75 & 2.3219 \\
\hline 8 & 60 & 0.143 & 1.0 & 90 & 2.705 \\
\hline 9 & 60 & 0.191 & 1.25 & 30 & 2.4108 \\
\hline 10 & 60 & 0.238 & 0.25 & 45 & 2.5919 \\
\hline 11 & 95 & 0.048 & 0.75 & 90 & 2.0033 \\
\hline 12 & 95 & 0.096 & 1.0 & 30 & 1.5196 \\
\hline 13 & 95 & 0.143 & 1.25 & 45 & 1.9891 \\
\hline 14 & 95 & 0.191 & 0.25 & 60 & 2.6587 \\
\hline 15 & 95 & 0.238 & 0.5 & 75 & 2.8615 \\
\hline 16 & 145 & 0.048 & 1.0 & 45 & 1.3275 \\
\hline 17 & 145 & 0.096 & 1.25 & 60 & 1.6402 \\
\hline 18 & 145 & 0.143 & 0.25 & 75 & 2.491 \\
\hline 19 & 145 & 0.191 & 0.5 & 90 & 2.3675 \\
\hline 20 & 145 & 0.238 & 0.75 & 30 & 1.7824 \\
\hline 21 & 225 & 0.048 & 1.25 & 75 & 1.4382 \\
\hline 22 & 225 & 0.096 & 0.25 & 90 & 2.2746 \\
\hline 23 & 225 & 0.143 & 0.5 & 30 & 1.9391 \\
\hline 24 & 225 & 0.191 & 0.75 & 45 & 2.0668 \\
\hline 25 & 225 & 0.238 & 1.0 & 60 & 2.2668 \\
\hline
\end{tabular}




\subsection{Mathematical model for surface roughness $\left(R_{a}\right)$}

In the present study, the second-order quadratic RSM based mathematical models was developed for surface roughness $\left(\mathrm{R}_{\mathrm{a}}\right)$, for PCD tool insert.

$\mathrm{R}_{\mathrm{a}}=1.19-0.0111 \mathrm{~V}+1.84 \mathrm{f}-1.64 \mathrm{~d}+0.0552 \Phi+0.000059 \mathrm{~V} * \mathrm{~V}-2.93 \mathrm{f}^{*} \mathrm{f}+1.36 \mathrm{~d} * \mathrm{~d}+0.000055 \Phi * \Phi-0.0122 \mathrm{~V} * \mathrm{f}+$ $0.00723 \mathrm{~V}^{*} \mathrm{~d}-0.000206 \mathrm{~V} * \Phi+4.05 \mathrm{f} * \mathrm{~d}+0.0141 \mathrm{f}^{*} \Phi-0.0381 \mathrm{~d} * \Phi$.

The statistical testing of the developed mathematical models was done by Fisher's statistical test for the analysis of variance (ANOVA). As per ANOVA for surface roughness is shown in Table 4, if the calculated value of F-ratio of the regression model is more than the standard tabulated value of the F-table for a given confidence interval, then the model is adequate within the confidence limit. It was found that the developed mathematical models are highly significant at $95 \%$ confidence interval as F-ratio for the developed models is greater than $2.83\left(F_{\text {-table }}(14,10,0.05)\right)$.

Table 4 Analysis of variance for $\mathrm{R}_{\mathrm{a}}$

\begin{tabular}{lllllll}
\hline Source & DF & SeqSS & Adj SS & Adj MS & F value & P value \\
Regression & 14 & 5.62209 & 5.62209 & 0.401578 & 48.82 & 0.000 \\
Linear & 4 & 4.78082 & 2.27955 & 0.569888 & 69.28 & 0.000 \\
Square & 4 & 0.50145 & 0.42760 & 0.106899 & 12.99 & 0.001 \\
Interaction & 6 & 0.33981 & 0.33981 & 0.056635 & 6.88 & 0.004 \\
Residual Error & 10 & 0.08226 & 0.08226 & 0.008226 & & \\
Total & 24 & 5.70435 & & & & \\
\hline
\end{tabular}

\section{Optimization of Surface Roughness by GA}

The selection of cutting parameters for optimization not only increases the utility for machining economics, but also the product quality to a great extent by minimizing the surface roughness parameters (Diwakar et al., 2011; Somashekara and Swamy, 2012). In this present study, an effort has been made to determine the optimum values of process parameters to obtain the best possible surface quality within the specific test range. Genetic algorithms are computerized optimization methods that work very similar to the principles of natural evolution. Based on Darwin's survival of-the fittest principles, GA's intelligent search procedure finds the best and fittest design solutions, otherwise difficult to find the best and fittest design solutions using other techniques. The solution of an optimization problem with genetic algorithm begins with a set of potential solution or chromosomes create population. The chromosomes evolve during several iterations called generations. The new generations are generated utilizing the crossover and mutation technique. The crossover combines two qualified individuals to exchange their genes to produce new offspring. Mutation involves flipping a single bit of chromosomes. The chromosomes are then evaluated employing a certain fitness criteria and the best ones are kept while the other are rejected. This process repeats until the chromosomes have the best fitness and is taken as the optimal solution for this problem. In this investigation, a mathematical model approach was used to formulate mathematical model from the experimental data for predicting the surface roughness $\left(\mathrm{R}_{\mathrm{a}}\right)$ using Response surface methodology. The developed model is then solved using an optimization technique to yield optimal parameters. In this investigation optimization problem is solved by coupling the RSM surface roughness model with the Genetic Algorithm. In turning of GFRP composites, optimization problem can be formulated in the following manner (Srikanth and Kamala, 2008):

Find: V (Cutting speed, $\mathrm{m} / \mathrm{min}$ ), f (feed, $\mathrm{mm} / \mathrm{rev}$ ), d (Depth of cut, $\mathrm{mm}), \Phi$ (fiber orientation angle, deg).

Minimum: $\mathrm{R}_{\mathrm{a}}(\mathrm{V}, \mathrm{f}, \mathrm{d}, \Phi)$,

Subjects to constraints: $\mathrm{Vmin} \leq \mathrm{V} \leq \mathrm{V} \max$.

$f \min \leq f \leq f \max$.

$\mathrm{d} \min \leq \mathrm{d} \leq \mathrm{d} \max$.

$\Phi \min \leq \Phi \leq \Phi$ max.

In this work, MATLAB 8.0 Toolbox GA was used to develop the GA program. The GA, written in MATLAB programming language, selects chromosomes based on objective value and level of constraint violation. The genetic parameters, where the optimized results are obtained are shown in Table 5.

Table 5 GA Parameters

\begin{tabular}{|l|c|}
\hline \multicolumn{1}{|c|}{ GA parameter } & Value \\
\hline Population size & 40 \\
\hline Fitness scaling & Rank \\
\hline Selection & Remainder \\
\hline Re-production & $\begin{array}{c}\text { Elite count-2 } \\
\text { Crossover fraction-0.75 }\end{array}$ \\
\hline Mutation & Uniform \\
\hline Crossover & Two point \\
\hline Number of generations & 100 \\
\hline
\end{tabular}




\section{Results and Discussions}

Surface roughness plays a predominant role in determining the turning accuracy. The study of surface roughness characteristics of GFRP composites dependent on many factors, it is more influenced by the cutting parameters like cutting speed, feed, depth of cut, etc., for a given machine tool and work piece set-up. The influence of different cutting parameters on turning of GFRP composites can be studied by using response graph as shown in figure 4 . Figure 4 shows the influence of process parameters on surfaces roughness. The observed surface roughness at high cutting speed is low as compared to low cutting speed. It can be observed that the surface roughness gradually decreases with increasing the cutting speed up to $145 \mathrm{~m} / \mathrm{min}$ and thereafter it increases slightly. This is because, at higher cutting speed debonding and fiber breakage are the reasons for poor surface roughness. The experimental results indicated that steady increase in the surface roughness is observed with increase in feed rate. It is observed from the figure that with the increase in the depth of cut up to $1.0 \mathrm{~mm}$, the surface roughness decreases thereafter increases slightly. The experimental results indicated that low surface roughness is observed for low fiber orientation angle as compared to high fiber orientation angle.

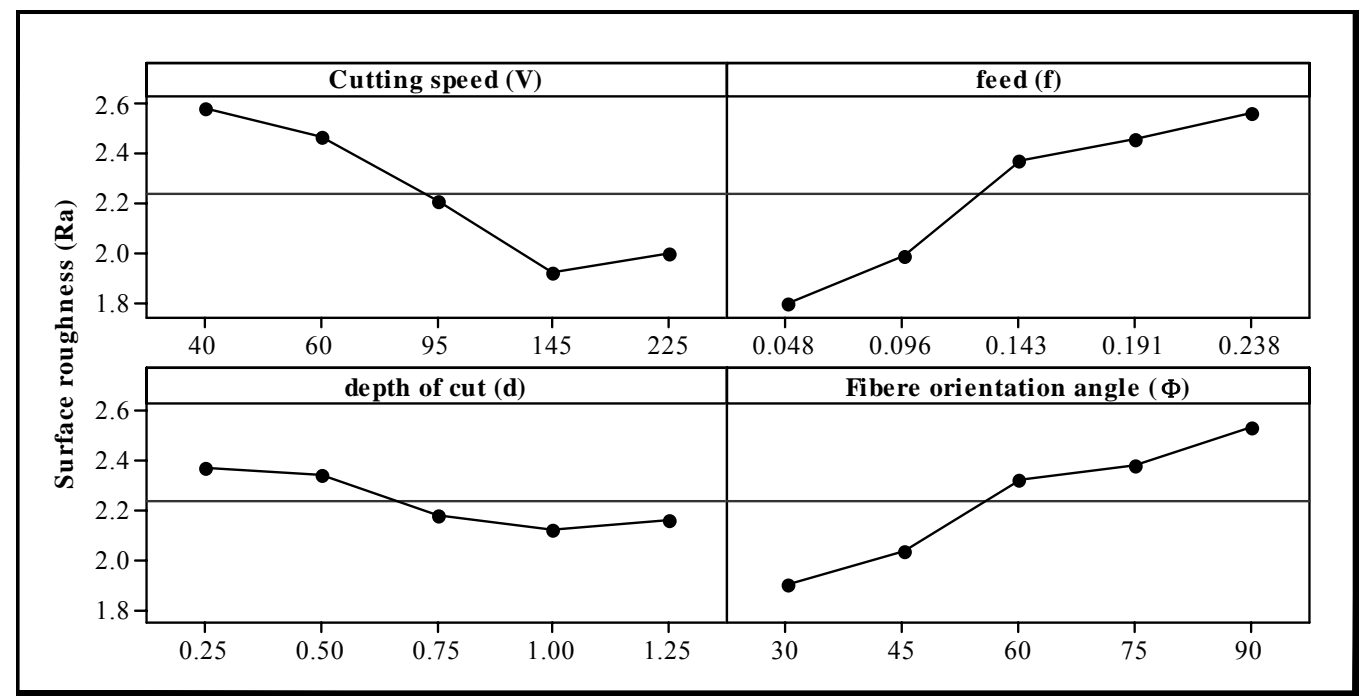

Figure: 4 Response Graph for main parameters on surface roughness with PCD tool

Table 6 Response table for surface roughness for PCD tool

\begin{tabular}{|c|c|c|c|c|}
\hline Level & $\begin{array}{c}\text { Cutting speed (V) } \\
\mathrm{m} / \mathrm{min}\end{array}$ & $\begin{array}{l}\text { Feed }(\mathrm{f}) \\
\mathrm{mm} / \mathrm{min}\end{array}$ & $\begin{array}{l}\text { Depth of cut (d) } \\
\text { mm }\end{array}$ & $\begin{array}{c}\text { Fiber orientation } \\
\text { angle }(\Phi) \text { deg }\end{array}$ \\
\hline 1 & 2.582 & 1.796 & 2.377 & 1.904 \\
\hline 2 & 2.474 & 1.989 & 2.340 & 2.033 \\
\hline 3 & 2.206 & 2.371 & 2.181 & 2.327 \\
\hline 4 & 1.922 & 2.460 & 2.123 & 2.382 \\
\hline 5 & 1.997 & 2.566 & 2.161 & 2.536 \\
\hline Delta & 0.661 & 0.770 & 0.254 & 0.631 \\
\hline Rank & 2 & 1 & 4 & 3 \\
\hline
\end{tabular}

Table 6 shows the influence of different cutting parameters on the surface roughness, from the table it is asserted that feed is the main parameter which affect the surface roughness followed by cutting speed fiber orientation angle and depth of cut.

\subsection{Diagnostic checking of the developed RSM model}

In the present investigation, a prediction check was made to test the adequacy of the developed models, (i.e.) construction of a plot of predicted versus actual values. The points show some scatter around the 45 degree line. The figure 5 shows how precisely the experimental value are close to the predicted values. 


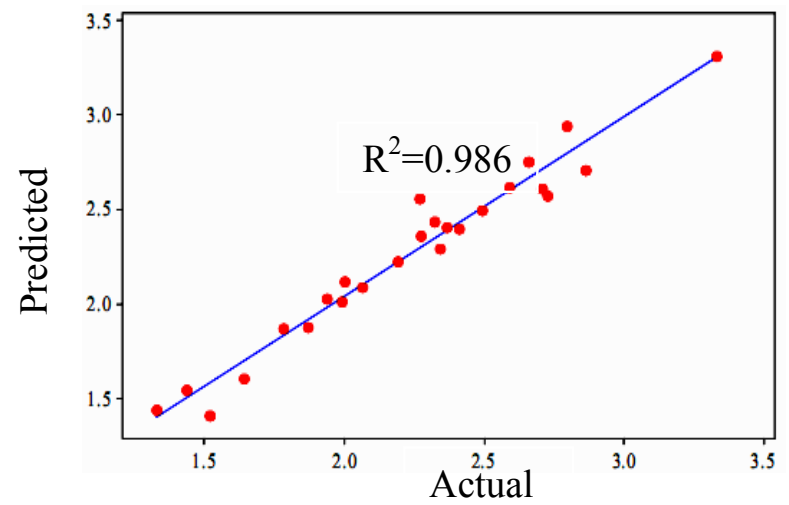

Figure 5 Predicted $\mathrm{K}_{\mathrm{a}} \mathrm{Vs}$ Actual $\mathrm{R}_{\mathrm{a}}$

The coefficient of determination $\left(\mathrm{R}^{2}\right)$ is also determined to test the goodness-of fit of the mathematical model, for the developed model the co-efficient of determination $\left(\mathrm{R}^{2}\right)$ is more than $95 \%$ which shows high correlation that exists between the model and experimental values.

\subsection{Genetic algorithm optimization for surface roughness}

Genetic Algorithm is effectively implemented to optimize the measured responses i.e., surface roughness in machining GFRP composite material. Table 6 shows the optimal process parameters for surface roughness. The performance of the fitness function with every generation and the coordinates of the best individual are shown in. The performance of the fitness function with every generation and the coordinates of the best individual are shown in Figure 6 (a-d). Figure 6 (a-d) to shows the genetic algorithm output plots for the surface roughness $\left(\mathrm{R}_{\mathrm{a}}\right)$ using PCD cutting tool insert. Plot (a) displays the best and mean values in each generation. The crossover fraction, population size and number of generations influence to achieve the best fitness value at each generation. Plot (b) shows the co-ordinates of the variables i.e., cutting speed (1), feed (2), depth of cut (3), and fiber orientation angle (4) for the best fitness values. Plot (c) shows the average distance between points in each generation. The amount of mutation influences the average distance between the points. As the amount of mutation decreases at every stage of generation, the average distance between points is approximately zero at the final generation. Plot (d) display the vertical lines at each generation, showing the range from smallest to the largest fitness value as well as mean fitness value. As amount of mutation decreases at every stage of generation the amount of diversity decreases in the subsequent generation and finally comes to zero.

The validity of the optimization procedure has been checked through confirmation experiments. The experiments have been performed with the optimized cutting conditions on GFRP composite material of $30^{\circ}$ fiber orientation angle. The confirmation result is found to be close with the optimal goal value with minimum deviation as shown in Table 7.
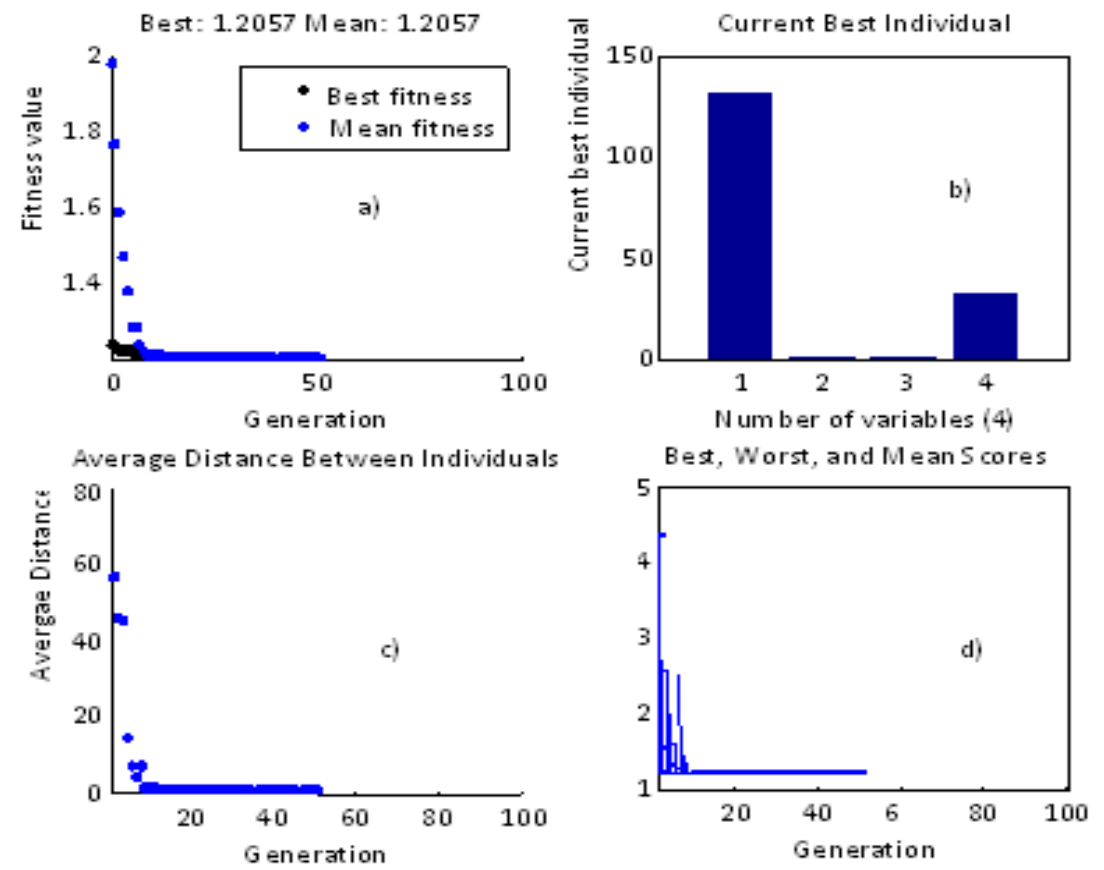

Fig. 6(a-d) Typical GA Plot for Surface roughness $\left(R_{a}\right)$ using PCD insert. 
Table 7 Optimum process parameters for surface roughness $\left(\mathrm{R}_{\mathrm{a}}\right)$ using PCD tool

\begin{tabular}{|l|c|}
\hline \multicolumn{1}{|c|}{ Process parameter } & value \\
\hline Cutting speed $(\mathrm{V})$ & $130.769 \mathrm{~m} / \mathrm{min}$ \\
feed (f) & $0.05 \mathrm{~mm} / \mathrm{rev}$ \\
depth of cut (d) & $0.697 \mathrm{~mm}$ \\
fiber orientation angle $(\Phi)$ & $32.60^{\circ}$ \\
\hline \multicolumn{1}{|c|}{ Response } & Result \\
\hline Surface roughness ( predicted by & $1.2057 \mu \mathrm{m}$ \\
GA) & \\
\hline Surface roughness (Confirmation & $1.2736 \mu \mathrm{m}$ \\
Experiment) & \\
\hline Error\% & 5.63 \\
\hline
\end{tabular}

\section{Conclusions}

In this study, an efficient optimization methodology using RSM and GA is introduced in minimizing surface roughness in turning of GFRP composites. To achieve the minimum surface roughness, the appropriate process parameters are determined. Cutting speed, feed, depth of cut and fiber orientation angle are considered as process parameters. In this investigation, I was considered work piece (fiber orientation angle) is one of the process parameter for which fiber orientation angle vary $30^{\circ}-90^{\circ}$ in steps of $15^{0}$ within this range only optimum fiber orientation angle was derived to minimize the surface roughness $\left(\mathrm{R}_{\mathrm{a}}\right)$. Based on the experimental observations the following conclusions are drawn.

- The developed second-order response surface model can be used to predic the surface roughness of the machined surfaces at different cutting conditions with the chosen range with $95 \%$ confidence intervals. Using such model, one can obtain remarkable savings in time and cost.

- The feed is the dominant parameter which affects the surface roughness of GFRP composites, followed by cutting speed, fiber orientation angle. Depth of cut shows a minimal effect on surface roughness compared to other parameters.

- To increase the quality of the surface finish, the RSM model is interfaced with an effective GA to find the optimum process parameter values.

- The optimized process parameters in turning of GFRP composite tubes with PCD cutting tool is: cutting speed range between $130 \sim 140 \mathrm{~m} / \mathrm{min}$, feed range is $0.048 \sim 0.05 \mathrm{~mm} / \mathrm{rev}$, depth of cut range is $0.6 \sim 1.0 \mathrm{~mm}$ and fiber orientation angle range is $30^{\circ} \sim 45^{\circ}$.

- The optimized conditions can be used to improve the machinability of GFRP composites.

\section{Acknowledgement}

The Authors are highly thankful to Dr. M. Santhiramudu, Chairman, RGM group of institutions for his encouragement and support.

\section{References}

Bhatnagar, N., Ramakrishnan, N., Naik N.K and Komandurai R., 1995. On the machining of fiber Reinforced plastics (FRP) composite laminates, Int J.Machine Tool Manuf, Vol. 35, No. 5, pp. 701-716.

Diwakar R.V., Krishnaiah G., Kumar A.H., Priya S.K., 2011. ANN-based prediction of surface roughness in turning, International Conference on Trends in Mechanical and Industrial Engineering (IC-TMIE 2011), Bangkok, December.

Evolkilickap,. 2010, Determination of optimum parameters on delamination in drilling of GFRP composites by Taghuchi Method, Indian Journal of Engineering \& material Science, Vol. 17, pp. 265-274.

Quintana G., Bustillo A., Ciurana J., 2012. Prediction, monitoring and control of surface roughness in high-torque milling machine operations, International Journal of Computer Integrated Manufacturing, Vol 25 , No. 12, pp. 1129-1138.

Hanafi i., khamlichi a., mata cabrera f., nunez lopez p.j., 2012. Prediction of surface roughness in turning of PEEK CF30 by using an artificial neural network, Journal of the Chinese Institute of Industrial Engineers, Vol. 29, No. 5, pp. 337-347.

König.W, Ch. Wulf, P. Grab and Willerscheid.H. 1985. A theory of machining of fiber reinforced plastics. CIRP AnnalsManufacturing Technology, Vol. 34, pp. 537-548.

Karhikeyan.R, Adalaraan. R., 2002. Optimization of machining Characteristics for $\mathrm{Al} / \mathrm{SiCp}$ composites using ANN/GA"Journal of Material science Technology, Vol. 18, No. 1, pp. 47-50.

Mitsuo Gen and Runwei Cheng, 1994. Genetic Algorithm and Engineering Design, John Wiley, New York.

Montgomery DC 1991, Design and analysis of experiments. John Wiley and sons, NewYork.

Palanikumar, K, 2008, Application of Taguchi and Response surface Methodology for surface Roughness In Machining Glass Fiber Reinforced Plastics by PCD tooling. International Journal of materials and Product Technology. Vol. 6, No. (1-2), 
pp. 19-27.

Palanikumar, K., Karunamoothy, L., and Karthikeyan, R., 2006, Assessment of Factors Influencing Surface Roughness on the Machining of Glass Fiber- Reinforced Composites, J. of Materials and Design, Vol. 27 No. 10, pp. 862-871.

Palanikumar, K.., Karunamoothy, L., and Karthikeyan, R, 2004. Optimization the machining parameters for minimum surface roughness in turning of GFRP composites using Design of Experiments, Journal of material science Technology, Vol. 20, No. 4, pp. 373-377.

Palanikumar K, Karunamoorthy. L Karthikeyan R and Latha B, 2006. Optimization of machining parameters in turning GFRP composites using Carbide (K20) tool based on Taguchi method and Fuzzy logics, Metals and Materials International, Vol.12, No.6, pp. 483-49.

Ross, PJ., 1996, Taguchi techniques for quality engineering. Mc Graw- Hill, New York.

Somashekara H.M., Swamy N.L., 2012. Optimizing surface roughness in turning operation using Taguchi technique and ANOVA, International Journal of Engineering Science and Technology, Vol. 4, No.5, pp. 1967-1973.

Srikanth T. and Kamala V., 2008. A real coded genetic algorithm for optimization of cutting parameters in turning, International Journal of Computer Science and Network Security, Vol. 8, No. 6., pp. 189-193.

Suresh. P.V.S., Rao. P.V., Deshmukh. S.G., 2002. A genetic algorithmic approach for optimization of surface roughness prediction model, Int. J. Mach. Tools and Manuf., Vol.42, pp. 675-680.

Sijo M.T and Biju.N,. 2010 Taguchi method for optimization of cutting parameters in turning operation, proc. of international Conference on Advances in Mech. Engg, pp. 103-105.

Surinderkumar, Meenu. Satsangi P S,, Sardana H K., 2012. Optimization of surface roughness in turning of glass fiber reinforced plastics (UD-GFRP) composites using polycrystalline diamond (PCD) cutting tool, Indian journal of Engineering \& materials Sciences, Vol. 19, pp. 163-174.

Surinderkumar, Meenu. Satsangi P S., 2012. A genetic algorithmic approach for optimization of surface roughness prediction model in turning using UD-GFRP composite, Indian journal of Engineering \& materials Sciences, Vol. 19, pp. 386-396.

Takeyama, H., and Lijama, N., 1988, Machinability of Glass Fiber Reinforced Plastics and Application of Ultrasonic machining, Annal of CIRP, Vol. 97, No.1, pp. 93-96.

Varma R., Abhishek K., Datta S., Mahapatra S.S., 2011. Fuzzy rule based optimization in machining of FRP composites, Turkish Journal of Fuzzy System, Vo. 2, No. 2, pp. 99-121.

\section{Nomenclature}

$\begin{array}{lll}\mathrm{V} & - & \text { Cutting speed } \\ \mathrm{d} & - & \text { Depth of cut } \\ \mathrm{f} & - & \text { feed rate } \\ \Phi & - & \text { Fiber orientation angle } \\ \mathrm{R}_{\mathrm{a}} & - & \text { Average surface roughness } \\ \beta & - & \text { Parameter vector } \\ \beta_{\mathrm{o}}, \beta_{\mathrm{i}}, \text { and } \beta_{\mathrm{ij}} & - & \text { Regression coefficients } \\ \varepsilon & - & \text { Noise or error term } \\ \mu \mathrm{m} & - & \text { Micrometer } \\ \text { ANOVA } & - & \text { Analysis of Variance } \\ \text { PCD } & - & \text { Poly-Crystalline Diamond } \\ \text { GFRP } & - & \text { Glass Fiber Reinforced Plastics (Polymers) }\end{array}$

\section{Biographical notes}

Dr. Syed Altaf Hussain, is a Professor in the Department of Mechanical Engineering, RGM College of Engineering \& Technology, Nandyal-518501, (A.P), India. He was graduated in Mechanical Engineering from Regional Engineering College, Warangal, A.P and Post graduated in the specialization of Machine Design from JNTU College of Engineering, Kakinada. He obtained Ph.D degree from JNT University, Anantapur, A.P, India. He has more than 17years of experience in teaching. His current area of research includes Machining of composite materials, Finite Element methods, Optimization, Simulation and Modeling.

Dr. V. Pandurangadu is a Professor in the Department of Mechanical Engineering, JNT University-Anantapur, Anantapur-515002, Andhra Pradesh, India. He has more than 30 years of experience in teaching and research. His current area of research includes Alternative fuels for an I.C Engines, Combustion of fuels, Machining of composite materials.

Dr. K. Palanikumar is a Principal, Sri Sairam Institute of Technology, Chennai-44, India. He obtained Ph.D degree in Mechanical Engineering from Anna university, Chennai, India. He has more than 20 years of experience in teaching and research. His current area of research includes Machining of composite materials, Modern manufacturing, Optimization, Simulation and Modeling.

Received February 2013

Accepted October 2013

Final acceptance in revised form October 2013 